\title{
Simultaneous and successive cutaneous two-point thresholds for vibration'
}

PAUL ESKILDSEN, ${ }^{2}$ AILENE MORRIS, CARTER C. COLLINS, and PAUL BACH-Y-RITA, Smith-Kettlewell Institute of Visual Sciences, Pacific Medical Center, San Francisco, Calif. 94115

An array of tactors, of a type used in a video-tactile visual substitution system, was used to determine two-point thresholds for vibration on the skin of the back. In the first study simultaneous stimulus presentations using the constant stimulus method resulted in a median threshold of $17.8 \mathrm{~mm}$. In the second study, both simultaneous and successive thresholds were near $11 \mathrm{~mm}$. These results differ from classical studies using touch calipers which give simultaneous thresholds of $68 \mathrm{~mm}$ and successive thresholds of $17 \mathrm{~mm}$.

Early research on two-point skin thresholds showed that with the "touch compass" thresholds varied with location on the skin, ranging from $1 \mathrm{~mm}$ on the tip of the tongue to $68 \mathrm{~mm}$ on the back and thigh, but tending to decrease toward the distal ends of the arms and legs (Woodworth \& Schlosberg, 1954; Vierordt, 1870). The transverse orientation of the threshold span on limbs and back resulted in lower thresholds than longitudinal orientation (Boring, 1942). The measurement of two-point thresholds was often difficult because of Vexirfehler, a phenomenon described as a paradoxical sensation of "two" even though only one point is being stimulated (Kottonkamp \& Ullrich, 1870; Boring, 1942). Although there is evidence that judgmental factors influence the prevalence of the phenomenon, there has been a suggestion that it represents sensations derived from two cutaneous sensory systems (Boring, 1916).

Much recent research in touch sensitivity has been directed towards evaluating stimulus parameters which show the usefulness of the skin as a channel of communication supplementary to the auditory and visual systems (Geldard, 1960; Bliss, 1962).

Previous studies in this laboratory have indicated that the two-point threshold for vibration on the skin of the back was well below the value obtained with the static stimulation of the "touch compass." Marked decrease in threshold size with practice was observed. Other findings showed only minor effects on thresholds from changes in stimulator tip size, orientation of the array, or specific region of the back (Morris, Collins, \& Bach-y-Rita, 1967).

TWO-POINT TOUCH THRESHOLDS

The present study was designed to evaluate two-point thresholds for the skin of the back with stimulation from a mechanical vibrator designed for use in a larger 400-point display. The larger display will be used in an auxiliary "visual" input system. By means of a two-dimensional video-tactile transducer system, pictorial information from a television camera will be projected onto the skin of the back as a dynamic image of vibration (Collins, 1967; Bach-y-Rita \& Collins, 1967).

Apparatus

The apparatus consisted of a row of five mechanically vibrating tactors set into a plastic box. The spacing between the five tactors was so arranged that interstimulus distances from 10 to $60 \mathrm{~mm}$ were available in steps of $10 \mathrm{~mm}$. The contact point for each tactor was a plastic hemisphere with $0.5 \mathrm{~mm}$ radius. The contact points were centered in $8-\mathrm{mm}$ apertures in a clear Lucite plate which lay flat on the skin. The vibrating tactor was in contact with the skin surface for about one-third of its period of excursion. Examined under stroboscopic illumination, the tactor was seen to depress the skin surface about $1 \mathrm{~mm}$ at maximum. Deformation of the skin was limited to the area immediately beneath the aperture, with the Lucite plate preventing the spread of traveling ripples across the surface of the skin. After reaching the maximum point in its excursion, the tactor withdrew from contact, rising about $3 \mathrm{~mm}$ above the skin surface. The skin, previously dimpled, was seen to follow immediately the withdrawing tactor and resume its flat surface. Thus, the stimulus to the skin at the point of contact was not a continuous sinusoid movement, but rather a series of pulses, or "pokes," limited to an area $8 \mathrm{~mm}$ across. The tactors were driven by 60 -cycle house current attenuated further with its own variable potentiometer while the overall level for the array could be adjusted by means of a variable auto-transformer.

Method

Five adult males were used as Ss. As $\mathrm{S}$ lay prone, the tactor device was lightly taped high on his back at the level of the scapula beginning at a point about $1 \mathrm{in}$. from the spine and extending laterally. The minimum perceptible level of vibration intensity was determined, with twice that level being used for the threshold observations. The tactor pairs were presented in random order using the constant stimulus method, with $S$ responding whether he felt one or two points being stimulated. Each tactor pair, representing one stimulus interval, was presented 24 times. Stimulus intervals used were $10,20,30$, and $40 \mathrm{~mm}$.

Results

Normal probability functions were fitted to the untransformed stimulus values using a modified probit analysis procedure (Finney, 1952). The threshold for each $S$ was taken to be that stimulus value corresponding to $p=0.50$ on the best-fit function. Thresholds for individual Ss ranged from $9.4 \mathrm{~mm}$ to $22.6 \mathrm{~mm}$, with a median of $17.8 \mathrm{~mm}$.

\section{SIMULTANEOUS AND SUCCESSIVE}

\section{TWO-POINT TOUCH THRESHOLDS}

Previous research with the touch compass has indicated that the two-point threshold for successive stimulation ranges from $1 / 4$ to $1 / 3$ the value for simultaneous stimulation (Woodworth, 1938). This experiment was designed to measure thresholds for vibratory stimuli under simultaneous and successive presentation.

Apparatus

The tactor array used in the previous experiment was mounted in the back of a dentist's chair. Stimuli were presented with $S$ sitting erect and leaning against the plastic face of the tactor array.

Method

Two female and three male adults were used as Ss in this experiment. Seven stimulus distances were used, ranging from 0 to $60 \mathrm{~mm}$ in steps of $10 \mathrm{~mm}$. The stimuli were presented in a randomized-blocks sequence, each stimulus being presented 12 times. S's task was to estimate the perceived distance between the two stimulated points. Possible effects of tactor array orientation were counterbalanced by reversing the orientation of the apparatus midway through the set of observations.

In the successive-stimuli condition, the first tactor was activated for a period of $1 \mathrm{sec}$ followed by a 1-sec waiting interval. Then the second tactor of the pair was activated. When the stimulus distance was zero, the same tactor was activated. In the simultaneous stimuli condition, both tactors were activated at the same time for a period of $2 \mathrm{sec}$. Each $S$ 
Table 1

Two-Point Thresholds for Five Ss Under Simultaneous and Successive Conditions Millimeters Separation

\begin{tabular}{lrrrrrrr}
\hline & \multicolumn{7}{c}{ Subject } \\
\cline { 2 - 7 } Condition & CJ & RT & PE & TN & JS & $\begin{array}{c}\text { Group } \\
\text { Mean }\end{array}$ \\
\hline Simultaneous & 8.08 & 10.50 & 12.18 & 9.07 & 16.95 & 11.36 \\
Successive & 7.25 & 13.60 & 9.69 & 7.28 & 12.92 & 10.15 \\
\hline
\end{tabular}

was used in both the simultaneous and successive conditions. Results

To determine the two-point threshold from the data, each S's responses were divided into two categories, "zero" and "not zero." The cumulative proportion of "not zero" responses was plotted as a function of stimulus distance.

Under this set of conditions, Ss frequently made "not zero" responses when only one tactor was activated. The proportions of these "false alarm" responses ranged from 0.08 to 0.50 with a median of 0.25 over the five Ss. In order to compare the results with the previous experiment, the threshold proportions were transformed using the "correction for guessing" formula: $p^{\prime}=(p-c) /(1-c)$, where $p^{\prime}$ is the transformed proportion, $p$ is the observed proportion, and $c$ is the proportion of "not zero" responses at the zero stimulus level. The transformed proportion, $\mathrm{p}^{\prime}$, ranges between zero and one, with the threshold defined as that stimulus corresponding to $\mathbf{p}^{\prime}=0.50$.

Cumulative normal probability functions were fitted to the "corrected" threshold data using a probit analysis method with untransformed stimulus values (Finney, 1952). Table 1 gives the obtained thresholds for each $S$ under the two stimulus conditions. Mean threshold over Ss for simultaneous presentation was $11.36 \mathrm{~mm}$, while mean threshold for successive presentation was $10.15 \mathrm{~mm}$. The difference between simultaneous and successive presentations was not statistically significant in the analysis of variance, with the obtained $\mathrm{F}=1.02$.

\section{DISCUSSION}

The two-point threshold distances for simultaneously presented vibratory stimuli are considerably less than those reported for static two-point calipers. In fact, the thresholds approximate those obtained when the caliper points are touched successively, as in the so-called "error of localization" experiment (Boring, 1942). In addition, there was no reduction in thresholds when vibratory stimuli were presented successively.

The results of the experiment were at variance with two-point thresholds for vibration reported by Geldard to be "many times greater" than those for static touch (Geldard, 1961). Differences in the nature of the vibratory stimuli used in Geldard's laboratory and those used in this laboratory may account for the difference in the magnitude of the thresholds obtained. The tactors used in the experiments reported by
Geldard were in constant contact with the skin under $100 \mathrm{~g}$ pressure. Vibration from one tactor, in setting up traveling ripples across the skin, tended to generate false localizations as the ripples moved against other inactive tactors. Since the tactors touched the skin under constant pressure, it is possible that adaptation had reduced sensitivity so that most of the remaining localization sense was derived from deeper tissues (Geldard, 1961).

The failure of these experiments to demonstrate a difference between simultaneous and successive two-point vibratory thresholds indicates that such differences using static stimuli are likely related to the reaction of the cutaneous touch system over time. Inhibitory action of the sort proposed by Békésy (1960), spreading in a wave from the two points of contact might be seen as generating a mutual masking effect on the touch sensations derived from the two points. The touched points could then be sensed as "two" only at a distance beyond the radius of effective inhibitory action. However, two vibrating stimuli presented as discrete "pokes" (as in the action of this laboratory's system) might be of sufficiently short duration that the inhibitory wave could not become fully developed, or would be of smaller magnitude, thus generating its masking effect over a shorter range.

\section{REFERENCES}

BACH-Y-RITA, P., \& COLLINS, C. C. Sensory plasticity and tactile image projection (abstract). Investigative Ophthalmology, 1967, 6, 669.

BÉKÉSY, G. von. Neural inhibitory units of the eye and skin. Quantitative description of contrast phenomena. Journal of the Optical Society of America, 1960, 50, 1060-1070.

BLISS, J. C. Kinesthetic-tactile communications. IRE Transactions, IT-8, 2, February 1962 .

BORING, E. G. Cutaneous sensation after nerve division. Quarterly Journal of Experimental Physiology, 1916, 10, 1-95.

BORING, E. G. Sensation and perception in the history of experimental psychology. New York: Appleton-Century-Crofts, 1942.

COLLINS, C. C. Tactile image projection (abstract). National Symposium on Information Display, 1967, 8, 290.

FINNEY, D. J. Probit analysis. (2nd ed.). Cambridge, England: University Press, 1952.

GELDARD, F. Some neglected possibilities of communication. Science, $1960,135,1583-1588$.

KOTTONKAMP, R., \& ULLRICH, H. Versuche uber den Raumsin der Haut der oberen Extremität, Zeitschrift fur Biologie, 1870, 6, 37-52. MORRIS, A., COLLINS, C. C., \& BACH-Y-RIT A, P. Factors influencing cutaneous sensitivity. Western Psychological Association, San Francisco, May 1967.

VIERORDT, K. Die Abhängigkeit der Ausbildung des Raumsinnes der Haut von den Beweglichkeit der Körpertheile. Zeitschrift für Biologie, $1870,6,53-72$.

WOODWORTH, R. S. Experimental psychology. New York: Henry Holt, 1938.

WOODWORTH, R. S., \& SCHLOSBERG, H. Experimental psychology (Rev. ed.). New York: Holt, Rinehart \& Winston, 1954. NOTES

1. This research was supported by Social and Rehabilitation Service Grant RD-2444-S-C1, NINDB Career Development Award K3 NB14,094 to Dr. Bach-y-Rita, NIH General Research Support Grant FR-05566, and the T. B. Walket Foundation, Inc.

2. Also at San Francisco State College, San Francisco, California.

(Continued from page 145)

HAWKER, J. R. The effects of training procedure, response availability, and response meaningfulness in multiple-choice paired-associate learning. Psychonomic Science, 1965a, 3, 329-330.

HAWKER, J.R. The effects of training procedure, response similarity, and number of response alternatives in multiple-choice paired-associate learning. Psychonomic Science, 1965b, 3, 331-332.

HAWKER, J. R. Training procedure and verbal-discrimination learning by mental retardates. Research Report No. 3, 1966, Austin State School, Behavioral Development Center, Austin, Texas.
HAWKER, J. R. The effects of training procedure and variations in the P-A paradigm on the learning of paired-associations. Psychonomic Science, $1967,7,347-348$.

NOTE

1. This study was supported by the Office of Education Grant No. OEG 0-8-070185-1750. 